\title{
Article \\ A One-Year Longitudinal Study: Changes in Depression and Anxiety in Frontline Emergency Department Healthcare Workers in the COVID-19 Pandemic
}

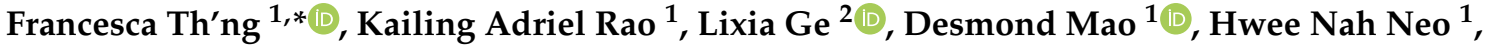 \\ Joseph Antonio De Molina ${ }^{2}$ and Eillyne Seow ${ }^{1}$ \\ 1 Acute \& Emergency Care Department, Khoo Teck Puat Hospital, 90 Yishun Central, \\ Singapore 768828, Singapore; rao.adriel.k@ktph.com.sg (K.A.R.); mao.desmond.r@ktph.com.sg (D.M.); \\ neo.hwee.nah@ktph.com.sg (H.N.N.); seow.eillyne@ktph.com.sg (E.S.) \\ 2 Health Services and Outcomes Research, National Healthcare Group, 3 Fusionopolis Link, \\ Singapore 138543, Singapore; Lixia_GE@nhg.com.sg (L.G.); \\ Joseph_Antonio_MOLINA@nhg.com.sg (J.A.D.M.) \\ * Correspondence: thng.francesca.cs@ktph.com.sg; Tel.: +65-98821657
}

\section{check for}

updates

Citation: Th'ng, F.; Rao, K.A.; Ge, L.; Mao, D.; Neo, H.N.; Molina, J.A.D.; Seow, E. A One-Year Longitudinal Study: Changes in Depression and Anxiety in Frontline Emergency Department Healthcare Workers in the COVID-19 Pandemic. Int. J. Environ. Res. Public Health 2021, 18 , 11228. https://doi.org/10.3390/ ijerph182111228

Academic Editor: Lucia Carboni

Received: 6 September 2021

Accepted: 22 October 2021

Published: 26 October 2021

Publisher's Note: MDPI stays neutral with regard to jurisdictional claims in published maps and institutional affiliations.

Copyright: (c) 2021 by the authors. Licensee MDPI, Basel, Switzerland. This article is an open access article distributed under the terms and conditions of the Creative Commons Attribution (CC BY) license (https:// creativecommons.org/licenses/by/ $4.0 /)$.

\begin{abstract}
Frontline healthcare workers (HCWs) fighting COVID-19 have been associated with depression and anxiety, but there is limited data to illustrate these changes over time. We aim to quantify the changes in depression and anxiety amongst Emergency Department (ED) HCWs over one year and examine the factors associated with these changes. In this longitudinal single-centre study in Singapore, all ED HCWs were prospectively recruited face-to-face. Paper-based surveys were administered in June 2020 and June 2021. Depression and anxiety were measured using DASS21. The results of $241 \mathrm{HCWs}$ who had completed both surveys were matched. There was significant improvement in anxiety amongst all HCWs (Mean: 2020: 2.85 ( \pm 3.19$)$ vs. 2021: 2.54 ( \pm 3.11$)$; Median: 2020: $2(0-4)$ vs. 2021: $2(0-4), p=0.045)$. HCWs living with elderly and with concerns about infection risk had higher odds of anxiety; those living with young children had lower odds of anxiety. There was significant worsening depression amongst doctors (Mean: 2020: 2.71 ( \pm 4.18$)$ vs. 2021: 3.60 ( \pm 4.50 ); Median: 2020: 1 (0-3) vs. 2021: $3(0-5), p=0.018)$. HCWs $\geq 41$ years, living with elderly and with greater concerns about workload had higher odds of depression. HCWs who perceived better workplace support and better social connectedness had lower odds of depression. In summary, our study showed significant improvement in anxiety amongst ED HCWs and significant worsening depression amongst ED doctors over one year. Age, living with elderly, and concerns about workload and infection risk were associated with higher odds of depression and anxiety.
\end{abstract}

Keywords: COVID-19; depression; anxiety; emergency department; healthcare workers; mental health

\section{Introduction}

The effects of the COVID-19 pandemic on the mental health outcomes (MHOs) of healthcare workers (HCWs) worldwide are well-documented. Since the start of the COVID19 pandemic more than a year ago, healthcare systems around the world continue to experience high levels of demand on all resources. With the emergence of highly resistant strains and multiple waves of infection in various countries, frontline HCWs have continued to risk infection, endure increased workloads, suffer trauma by witnessing first-hand high levels of death and morbidity, as well as deal with challenges arising from resource allocation. A large meta-analysis by Batra et al., consisting of 65 studies carried out amongst HCWs, showed that the pooled prevalence for anxiety was $34.4 \%$, depression $31.8 \%$, stress $40.3 \%$, post-traumatic stress syndrome $11.4 \%$, insomnia $27.8 \%$, psychological distress $46.1 \%$ and burnout $37.4 \%$ [1]. There was higher prevalence of depression and anxiety among females, nurses and frontline workers. A study carried out in UK and USA found that frontline HCWs had at least a threefold increased risk of reporting a positive 
test for COVID-19 compared with the general community [2]. In addition to what has been mentioned in the meta-analysis, poorer MHOs amongst frontline HCWs have also been associated with those living alone and worries about being infected or infecting others [3-8].

There are currently limited published longitudinal studies amongst frontline HCWs to quantify the ongoing psychological impact of COVID-19 even as the pandemic situation waxes and wanes. Two large prospective longitudinal studies amongst Chinese frontline HCWs showed slightly different outcomes: one study [9] found significantly worse psychiatric status (somatization, obsessive-compulsiveness, interpersonal sensitivity, depression, anxiety, hostility, phobic anxiety, paranoid ideation, psychoticism) and sleep quality a month later; and the other [5] found significantly higher risks for depression, anxiety and PTSD symptoms during the outbreak period compared to the stable period of the pandemic a month later. On a smaller scale, a study in Belgium [10] amongst Intensive Care Unit (ICU) nurses in April 2020 showed that they had improved depression, anxiety and somatization over a two-month period. Similarly, a study done in Singapore [6] in March 2020 amongst residents in training showed that residents who were deployed to the higher risk National Centre for Infectious Diseases (NCID) to manage patients with COVID-19 had lower perceived stress and stigma at the three-month follow-up. To date, there have been no published longitudinal studies to assess the changes in depression and anxiety in individual frontline Emergency Department (ED) HCWs over a more prolonged period, other than the time frames in the above-mentioned studies.

In general, longitudinal studies are important to detect changes in the characteristics of the sample population, on a group and individual level. Longitudinal studies conducted in military personnel with prolonged combat exposure had shown wide-ranging adverse effects on health behaviours and mental health [11]. In the healthcare context, the effects of fighting a prolonged pandemic that has spanned longer than a year are unknown. Our previous cross-sectional study [12] among ED HCWs in June 2020 showed that $27.5 \%$ of HCWs screened positive for depression and $34.3 \%$ for anxiety. Females were more likely to have anxiety, and those living with elderly had significantly higher median anxiety scores.

This longitudinal study is to help us to identify the factors associated with poorer MHOs in our cohort of frontline ED HCWs a year since the first wave of the pandemic. This will allow us to optimize the support for their wellbeing during their fight in this protracted pandemic. Resilience is the ability to adapt to adversity or stressful situations. During a crisis like the COVID-19 outbreak, it has been shown that enhancing resilience and coping strategies has important effects on enhancing mental health outcomes. Predictors of good resilience include having pursued hobbies and a positive family environment [13], and knowing the relationship between these coping strategies and MHOs would be useful. As of the time of the second survey in June 2021, the COVID-19 pandemic in Singapore has been more controlled compared to its peak in June 2020, as quantified by the reduced daily COVID-19 cases and hospitalisations. We aimed to (1) quantify the changes in depression and anxiety in our cohort of frontline ED HCWs over the year; and (2) identify factors associated with depression and anxiety. We hypothesise that depression and anxiety amongst individual HCWs will generally improve with the pandemic situation being more controlled compared to its peak last year.

\section{Materials and Methods}

\subsection{Study Design and Participants}

This is a longitudinal single-centre study carried out on ED HCWs in Khoo Teck Puat Hospital (KTPH), Singapore. The study hospital is a 795-bed acute hospital, and the ED sees an average of 135,000 patients a year. To date (July 2021), the study ED has seen 1635 COVID-19 positive patients.

The data used for this study were collected from two waves of surveys conducted amongst the ED HCWs in KTPH. The first wave was conducted from 1 to 9 June 2020 [12] 
and the second wave was conducted one year after from 1 to 16 June 2021. The methodology for the first wave survey has been described previously [12].

The inclusion criteria for this study were all HCWs from this single-centre's ED. HCWs who had resigned or had transferred out of the department during the 1 year were excluded from the second survey. As participation was voluntary, HCWs who did not wish to participate were not included in the survey.

Out of the 327 ED HCWs who responded to the first survey in 2020, 19 had resigned and 22 who were temporarily deployed to ED had left ED before the second survey was conducted. These $41 \mathrm{HCWs}$ were excluded from the second survey. As such, $286 \mathrm{ED}$ HCWs were invited to take part in the second wave survey from 1 to 16 June 2021. Written consent was obtained from each participant. Paper-based consent forms and survey questionnaires were handed out to the eligible ED HCWs during roll calls. The ED register list was used to ensure that surveys were only handed out to each participant once. Those who were willing to take part were instructed to return the signed consent form and completed questionnaire to the investigators, either by handing in at the end of their work shift or by dropping it off directly into a collection box at the ED office. The ethic review of this study was approved by the National Healthcare Group Domain Specific Review Board (Reference number: 2020/00653 and 2021/00336).

Out of the 286 eligible ED HCWs, 279 completed the second wave survey (response rate: $97.6 \%$ ). See Figure 1. Responses from the first and second waves of survey were anonymised, but they were matched based on the last four digits of the HCW's handphone number, gender, ethnicity, and profession. In total, 241 participants were matched and their responses to both the first and second waves of survey were included for data analysis.

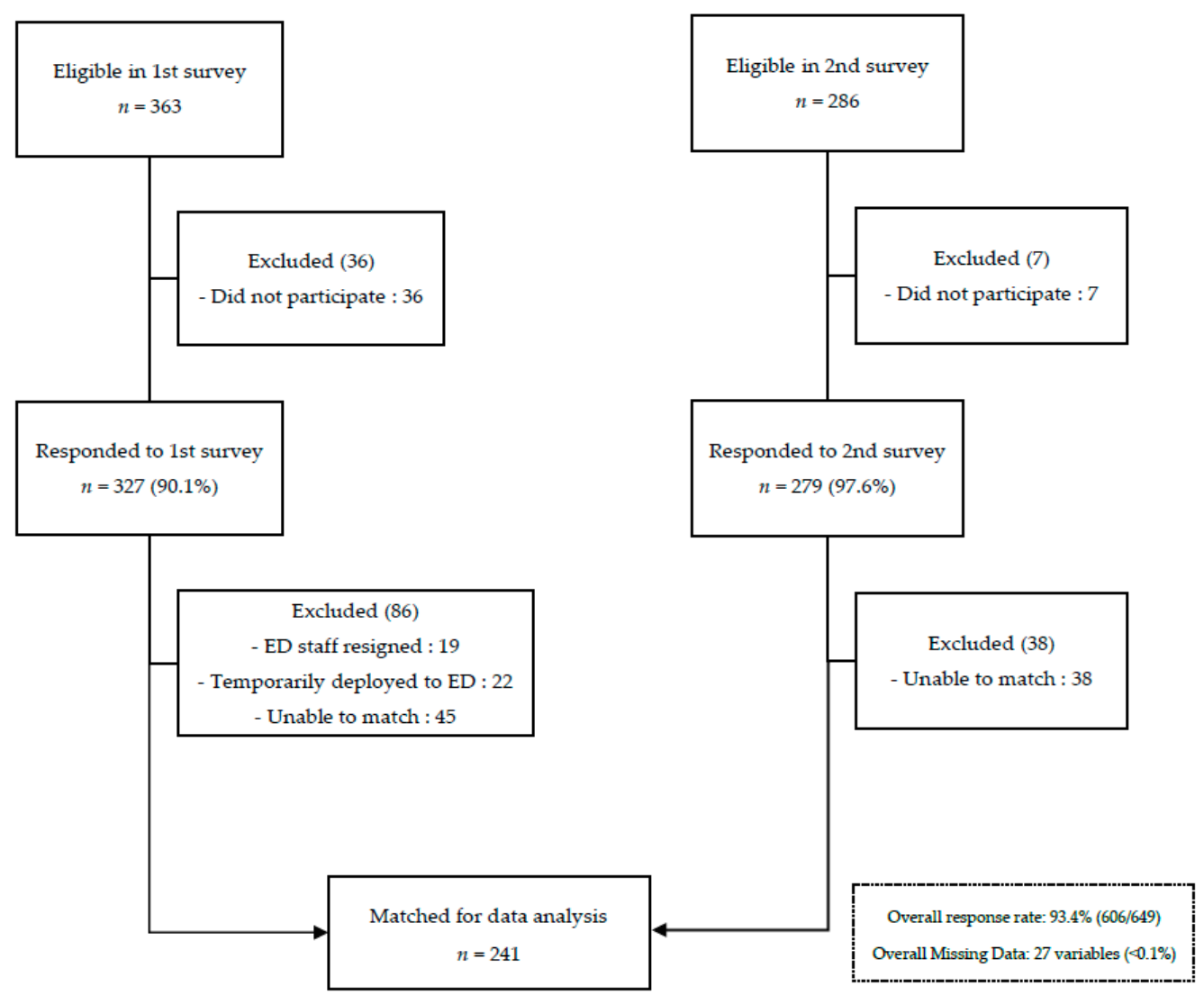

Figure 1. Flow diagram of the COVID-19 longitudinal study carried out in June 2020 (1st survey) and June 2021 (2nd survey).

There has been no specific intervention implemented by the study group during and between the two surveys. Changes of COVID-19 safety measures through the one-year 
period included easing of national lockdown rules (e.g., being able to see family and friends from a different household) and a period of easing of infective measures at workplace (e.g., surgical masks could be worn in non-infective areas instead of N95). COVID-19 vaccination was also offered to all HCWs for free since the beginning of 2021. Table A1 illustrates the timeline of main changes through the year in Singapore.

\subsection{Outcome Measures}

Depression and anxiety were measured using the validated Depression, Anxiety and Stress Scale (DASS-21) [14]. DASS-21 is a 21-item self-report questionnaire and each MHO domain contains 7 items. The Depression domain assesses dysphoria, hopelessness, devaluation of life, self-deprecation, lack of interest, anhedonia and inertia; and the Anxiety domain assesses autonomic arousal, skeletal musculature effects, situational anxiety and subjective experience of anxious effect. Scores for the Depression and Anxiety domains were calculated by summing the scores for the relevant items in the respective domain. Scores were then multiplied by two to categorise individual HCWs into two groups (normal vs. positive for depression or anxiety). A positive score for depression was defined as $>9$ and for anxiety $>7$.

Demographic information including age group, gender, ethnicity, occupation and living environment were included in both surveys (Figure A1). For the 2021 survey, we included a question on vaccination status of HCWs. Further questions to capture $\mathrm{HCWs}^{\prime}$ concerns and perceptions (Figure A1: Sections D and E of survey), using a Likert scale with 6 options ( $1=$ Strongly Disagree to $6=$ Strongly Agree), were developed based on experts' opinions (Study team's ED consultants, senior nurse and biostatisticians), but they were not part of a validated instrument. These questions were later categorised based on their content relevance for data analysis (Figure A2), namely, concerns and perceptions about COVID-19 infection risk, workplace support, workload, working environment and social connectedness.

\subsection{Statistical Analysis}

Descriptive analyses were conducted to show the demographic characteristics of the included study sample. Frequency and percentage were used to describe categorical variables. Mean and standard deviation (SD) or median and inter-quantile range (IQR) were used to describe continuous variables. The distribution of the severity and status of each MHO in 2020 and 2021 were compared using Fisher's Exact tests and their median scores were compared using Mann-Whitney U tests. Fisher's exact tests for categorical variables and independent $t$-tests or Mann-Whitney $U$ tests for continuous variables were performed to determine differences in demographic characteristics, as well as individual items regarding concerns and perceptions about infection, working environment, workplace support and workload and their average scores by status of each MHO.

Fixed-effects and random-effects logistic regressions on panel data were performed to identify the potential factors that were associated with individual MHOs. In each model, the status of each $\mathrm{MHO}$ (binary variable) was the dependent variable. The factors that were identified to be associated with any MHO $(p<0.1)$ in bivariate analysis, namely demographic characteristics, individual coping items (binary), domain scores of concerns about infection, working environment and workload, perceptions about workplace support and social connectedness, were included as the independent variables. Odds ratios (OR) and $95 \%$ confidence intervals (CIs) were reported. Hausman tests were conducted to examine whether fixed-effects or random-effects model was more appropriate. If $p<0.05$ for the Hausman test, fixed-effects models will be used, otherwise, random-effects models will be chosen. All analyses were performed using Stata/SE 16.1. $p<0.05$ was set as the level of significance. 


\section{Results}

\subsection{Characteristics of Study Sample}

Amongst staff eligible to participate, the overall response rate for both surveys was 93.4\% (Figure 1). Table 1 shows the demographic characteristics of the 241 matched participants. The majority of the participants were female $(71.8 \%)$, nurses $(71.4 \%)$ and Chinese (38.6\%). Compared to 2020, there was a significant increase in number of participants with family member(s) or friend(s) who had contracted COVID-19 in $2021(2020: \mathrm{n}=20(8.3 \%)$ vs. $2021: \mathrm{n}=39(16.2 \%) ; p=0.008)$. As vaccination among HCWs in our hospital started in January 2021,91.3\% had received at least one dose of the COVID-19 vaccine at the time of the second survey.

Table 1. Characteristics of matched participants $(n=241)$ in 2020 and 2021 . There were 58 doctors $(24.1 \%)$ and 183 nursing staff $(75.9 \%)$ in each year's cohort.

\begin{tabular}{|c|c|c|c|}
\hline Characteristics & June 2020 & June 2021 & $p$-Value \\
\hline \multicolumn{4}{|l|}{ Gender $(n, \%)$} \\
\hline Female & $173(71.8)$ & $173(71.8)$ & \multirow{2}{*}{-} \\
\hline Male & $68(28.2)$ & $68(28.2)$ & \\
\hline \multicolumn{4}{|l|}{ Ethnicity $(\mathrm{n}, \%)$} \\
\hline Chinese & $93(38.6)$ & $93(38.6)$ & \multirow{5}{*}{-} \\
\hline Malay & $25(10.3)$ & $25(10.3)$ & \\
\hline Indian & $34(14.1)$ & $34(14.1)$ & \\
\hline Filipino & $77(32.0)$ & $77(32.0)$ & \\
\hline Others & $12(5.0)$ & $12(5.0)$ & \\
\hline \multicolumn{4}{|l|}{ Age group in years $(n, \%)$} \\
\hline $21-30$ & $104(43.2)$ & $86(35.7)$ & \multirow{5}{*}{0.573} \\
\hline $31-40$ & $100(41.5)$ & $113(46.9)$ & \\
\hline $41-50$ & $28(11.6)$ & $32(13.3)$ & \\
\hline $51-60$ & $6(2.5)$ & $6(2.5)$ & \\
\hline$>60$ & $3(1.2)$ & $4(1.7)$ & \\
\hline \multicolumn{4}{|l|}{ Marital status (n,\%) } \\
\hline Single & $126(52.3)$ & $115(47.7)$ & \multirow{4}{*}{0.605} \\
\hline Married & $113(46.9)$ & $122(50.6)$ & \\
\hline Separated/Divorced & $1(0.4)$ & $3(1.2)$ & \\
\hline Widowed & $1(0.4)$ & $1(0.4)$ & \\
\hline \multicolumn{4}{|l|}{ Occupation $(\mathrm{n}, \%)$} \\
\hline Doctors: Senior doctors & $22(9.1)$ & $22(9.1)$ & \multirow{4}{*}{-} \\
\hline Junior doctors & $36(14.9)$ & $36(14.9)$ & \\
\hline Nursing staff: Nurses & $172(71.4)$ & $172(71.4)$ & \\
\hline Healthcare assistants & $11(4.6)$ & $11(4.6)$ & \\
\hline \multicolumn{4}{|l|}{ Past medical history $(\mathrm{n}, \%)$} \\
\hline Yes & $10(4.2)$ & $13(5.4)$ & \multirow{2}{*}{0.522} \\
\hline No & $231(95.9)$ & $228(94.6)$ & \\
\hline \multicolumn{4}{|c|}{ Living with young children (<12 years old) (n,\%) } \\
\hline Yes & $36(14.9)$ & $49(20.3)$ & \multirow{2}{*}{0.120} \\
\hline No & $205(85.1)$ & $192(79.7)$ & \\
\hline \multicolumn{4}{|l|}{ Living with elderly (>65 years old) $(n, \%)$} \\
\hline Yes & $34(14.1)$ & $41(17.0)$ & \multirow{2}{*}{0.379} \\
\hline No & $207(85.9)$ & $200(83.0)$ & \\
\hline
\end{tabular}


Table 1. Cont.

\begin{tabular}{|c|c|c|c|}
\hline Characteristics & June 2020 & June 2021 & $p$-Value \\
\hline \multicolumn{4}{|l|}{ Lives alone $(\mathrm{n}, \%)$} \\
\hline Yes & $35(14.5)$ & $41(17.0)$ & \multirow{2}{*}{0.453} \\
\hline No & $206(85.5)$ & $200(83.0)$ & \\
\hline \multicolumn{4}{|l|}{ Practices a religion $(\mathrm{n}, \%)$} \\
\hline Yes & $181(75.1)$ & $182(75.5)$ & \multirow[b]{2}{*}{0.916} \\
\hline No & $60(24.9)$ & $59(24.5)$ & \\
\hline \multicolumn{4}{|l|}{ Has family or close friend with COVID-19 (n,\%) } \\
\hline Yes & $20(8.3)$ & $39(16.2)$ & \multirow[b]{2}{*}{0.008} \\
\hline No & $221(91.7)$ & 202 (83.8) & \\
\hline \multicolumn{4}{|l|}{ COVID-19 vaccinated ( 1 or 2 doses) $(n, \%)$} \\
\hline Yes & - & $220(91.3)$ & \multirow{2}{*}{-} \\
\hline No & - & $21(8.7)$ & \\
\hline Concerns about infection risk (Mean $\pm \mathrm{SD}$ ) & $4.18 \pm 0.80$ & $3.92 \pm 0.85$ & 0.000 \\
\hline Concerns about working environment $($ Mean \pm SD) & $4.14 \pm 0.84$ & $3.94 \pm 0.99$ & 0.003 \\
\hline Concerns about workload (Mean \pm SD) & $4.06 \pm 0.98$ & $4.37 \pm 0.92$ & 0.000 \\
\hline Social connectedness (Mean \pm SD) & $4.55 \pm 0.65$ & $4.40 \pm 0.69$ & 0.002 \\
\hline Workplace support (Mean \pm SD) & $4.83 \pm 0.67$ & $4.63 \pm 0.72$ & 0.000 \\
\hline
\end{tabular}

Compared to the first survey, HCWs reported significantly fewer concerns about infection risk (Mean $( \pm S D)$ : 2020: $4.18( \pm 0.80)$ vs. 2021: $3.92( \pm 0.85)$ ) and fewer concerns about their working environment in 2021 (2020: 4.14 ( \pm 0.84$)$ vs. 2021: 3.94 ( \pm 0.99$)$ ). In 2021, HCWs also reported significantly greater concerns about workload (2020: $4.06( \pm 0.98)$ vs. 2021: 4.37 ( \pm 0.92$)$ ), lesser social connectedness (2020: 4.55 ( \pm 0.65$)$ vs. 2021: $4.40( \pm 0.69)$ ) and had perceived lesser workplace support (2020: 4.83 ( \pm 0.67$)$ vs. $2021: 4.63( \pm 0.72)$ ). See Table 1.

\subsection{Mental Health Outcomes}

\subsubsection{Depression}

There was no significant difference in the distribution of severity of depression between both years (Table 2). A total of $25.3 \%$ of HCWs screened positive for depression in 2020 , and $28.6 \%$ in $2021(p=0.412)$. There was significant worsening in depression scores amongst doctors in 2021 (Mean ( \pm SD): 2020: $2.71 \pm 4.18$ vs. 2021: $3.60 \pm 4.50$; Median (IQR): 2020: 1 (0-3) vs. 2021: $3(0-5), p=0.018)$ (Table 3).

Table 2. Longitudinal changes of depression and anxiety by severity in June 2020 and June 2021.

\begin{tabular}{|c|c|c|c|c|c|c|}
\hline \multirow{2}{*}{ Depression in 2020 (n) } & \multicolumn{6}{|c|}{ Depression in $2021(n, \%)$} \\
\hline & Normal & Mild & Moderate & Severe & Extremely Severe & Total in 2020 \\
\hline Normal & $149(82.3)$ & $14(7.8)$ & $16(8.9)$ & 0 & $1(0.6)$ & 180 \\
\hline \multicolumn{7}{|l|}{ Positive for Depression } \\
\hline Mild & $15(55.6)$ & $6(22.2)$ & $3(11.1)$ & 0 & $3(11.1)$ & 27 \\
\hline Moderate & $7(29.2)$ & $6(24.0)$ & $6(24.0)$ & $3(12.5)$ & $2(8.3)$ & 24 \\
\hline Severe & 0 & 0 & $2(40.0)$ & 0 & $3(60.0)$ & 5 \\
\hline Extremely severe & $1(20.0)$ & $2(40.0)$ & $1(20.0)$ & 0 & $1(20.0)$ & 5 \\
\hline Total in 2021 & $172(71.4)$ & $28(11.6)$ & $28(11.6)$ & $3(1.2)$ & $10(4.1)$ & 241 \\
\hline
\end{tabular}


Table 2. Cont.

\begin{tabular}{|c|c|c|c|c|c|c|}
\hline \multirow{2}{*}{ Anxiety in 2020 (n) } & \multicolumn{6}{|c|}{ Anxiety in $2021(n, \%)$} \\
\hline & Normal & Mild & Moderate & Severe & Extremely Severe & Total in 2020 \\
\hline Normal & $144(86.2)$ & $9(5.4)$ & $12(7.2)$ & 0 & $2(1.2)$ & 167 \\
\hline \multicolumn{7}{|l|}{ Positive for Anxiety } \\
\hline Mild & $16(66.7)$ & $1(4.2)$ & $5(20.8)$ & $1(4.2)$ & $1(4.2)$ & 24 \\
\hline Moderate & $11(37.9)$ & $3(10.3)$ & $11(37.9)$ & $4(13.8)$ & 0 & 29 \\
\hline Severe & $4(40.0)$ & 0 & $3(30.0)$ & $1(10.0)$ & $2(20.0)$ & 10 \\
\hline Extremely severe & $1(10.0)$ & $1(10.0)$ & $1(10.0)$ & $2(20.0)$ & $5(50.0)$ & 10 \\
\hline Total in 2021 & $176(73.0)$ & $14(5.8)$ & $32(13.3)$ & $8(3.3)$ & $10(4.1)$ & 241 \\
\hline
\end{tabular}

Table 3. Depression and anxiety scores amongst matched HCWs $(n=241)$ and its subgroups of doctors $(n=58)$ and nursing staffs $(n=183)$.

\begin{tabular}{|c|c|c|c|c|c|}
\hline MHOs & $\begin{array}{c}\text { June } 2020 \\
\text { Mean }( \pm \text { SD) }\end{array}$ & $\begin{array}{c}\text { June } 2021 \\
\text { Mean }( \pm \text { SD) }\end{array}$ & $\begin{array}{c}\text { June } 2020 \\
\text { Median } \\
\text { (IQR) }\end{array}$ & $\begin{array}{c}\text { June } 2021 \\
\text { Median } \\
\text { (IQR) }\end{array}$ & $p$-Value * \\
\hline \multicolumn{6}{|c|}{ All HCWs $(n=241)$} \\
\hline Depression & $3.05 \pm 3.50$ & $3.45 \pm 3.91$ & $2(0-5)$ & $2(0-5)$ & 0.181 \\
\hline Anxiety & $2.85 \pm 3.19$ & $2.54 \pm 3.11$ & $2(0-4)$ & $2(0-4)$ & 0.045 \\
\hline \multicolumn{6}{|c|}{ Doctors $(n=58)$} \\
\hline Depression & $2.71 \pm 4.18$ & $3.60 \pm 4.50$ & $1(0-3)$ & $3(0-5)$ & 0.018 \\
\hline Anxiety & $2.02 \pm 3.0$ & $1.78 \pm 2.59$ & $1(0-3)$ & $1(0-3)$ & 0.259 \\
\hline \multicolumn{6}{|c|}{ Nursing Staff $(n=183)$} \\
\hline Depression & $3.16 \pm 3.27$ & $3.40 \pm 3.72$ & $2(1-5)$ & $2(0-5)$ & 0.815 \\
\hline Anxiety & $3.12 \pm 3.18$ & $2.79 \pm 3.23$ & $2(1-4)$ & $2(0-4)$ & 0.086 \\
\hline
\end{tabular}

* Wilcoxon matched-pairs signed-rank test.

HCWs aged 41 years or older (Odds Ratio: 7.9, 95\% CI: 1.1-55.6), those living with elderly (OR: 6.3, 95\% CI: 1.8-21.8) and those with greater concerns about workload (OR: 2.0, 95\% CI: 1.2-3.4) had significantly higher odds of developing depression (Table 4). The questions in the workload category that were significantly associated with depression were "There is a lack of manpower in the fever area" $(p=0.002)$ and "I spend longer hours at work since the outbreak started" $(p=0.010)$ (Table A2). HCWs who perceived better workplace support (OR: $0.5,95 \%$ CI: $0.2-0.9$ ) and social connectedness (OR: $0.3,95 \%$ CI: 0.1-0.6) had significantly lower odds of developing depression.

\subsubsection{Anxiety}

There was no significant difference in the distribution of severity of anxiety between both years (Table 2). A total of 30.7\% of HCWs were screened positive for anxiety in 2020, and $27.0 \%$ in 2021 ( $p=0.366)$. There was a significant improvement in anxiety scores in our study cohort (Mean: 2020: $2.85 \pm 3.19$ vs. 2021: $2.54 \pm 3.11$; Median: 2020: 2 (0-4) vs. 2021: $2(0-4), p=0.045)$ (Table 3).

HCWs living with elderly (OR: 7.9, 95\% CI: 2.3-27.2) and those with greater concerns about COVID-19 infection risk (OR: 1.8, 95\% CI: 1.0-3.0) had significantly higher odds of developing anxiety; those living with young children (OR: 0.1, 95\% CI: 0-0.6) had significantly lower odds of developing anxiety (Table 4).

Eighty-six HCWs were excluded from the 2020 cohort for data analysis: 19 ED staff had resigned, 22 were temporarily deployed to our ED and had left, and 45 did not match to the 2021 responses (Figure 1). This excluded group had a significantly higher percentage of anxiety (Excluded: $44.2 \%$ vs. Included: $30.7 \%, p=0.024)$ and significantly higher anxiety scores (Excluded: $3(1-6)$ vs. Included: $2(0-4), p=0.038)$ compared to the HCWs included in the 2020 cohort (Table A3). 
Table 4. The association between individual factors and each MHO (random-effects logistic regressions).

\begin{tabular}{|c|c|c|c|c|}
\hline & \multicolumn{2}{|c|}{ Depression } & \multicolumn{2}{|c|}{ Anxiety } \\
\hline & OR $(95 \% \mathrm{CI})$ & $p$-Value & OR $(95 \%$ CI $)$ & $p$-Value \\
\hline \multicolumn{5}{|l|}{ Age group (Ref: <31 years) } \\
\hline $31-40$ years & $1.6(0.5-4.8)$ & 0.419 & $0.5(0.2-1.6)$ & 0.245 \\
\hline 41 years and above & $7.9(1.1-55.6)$ & 0.039 & $1.6(0.3-9.6)$ & 0.631 \\
\hline Female & $1.0(0.3-3.2)$ & 0.970 & $2.3(0.7-7.6)$ & 0.178 \\
\hline \multicolumn{5}{|l|}{ Ethnicity (Ref: Chinese) } \\
\hline Filipino & $0.7(0.2-2.6)$ & 0.617 & $0.5(0.1-1.7)$ & 0.258 \\
\hline Others & $0.8(0.2-2.4)$ & 0.664 & $1.3(0.4-4.1)$ & 0.703 \\
\hline Married & $0.4(0.1-1.1)$ & 0.084 & $1.6(0.6-4.1)$ & 0.374 \\
\hline \multicolumn{5}{|l|}{ Occupation (Ref: Physician) } \\
\hline Nursing staff & $1.0(0.3-3.9)$ & 0.998 & $1.4(0.3-5.5)$ & 0.664 \\
\hline Number of years in occupation & $0.9(0.8-1.0)$ & 0.019 & $1.0(0.9-1.1)$ & 0.382 \\
\hline Living with elderly (Ref: No) & $6.3(1.8-21.8)$ & 0.004 & $7.9(2.3-27.2)$ & 0.001 \\
\hline Living with young children (Ref: No) & $0.7(0.2-2.6)$ & 0.601 & $0.1(0-0.6)$ & 0.006 \\
\hline Coping Strategies_Religion (Ref: No) & $0.8(0.2-2.8)$ & 0.753 & $2.7(0.7-10.3)$ & 0.138 \\
\hline Concerns about infection risk & $1.2(0.7-2.1)$ & 0.485 & $1.8(1.03-3.0)$ & 0.039 \\
\hline Concerns about workload & $2.0(1.2-3.4)$ & 0.008 & $1.4(0.9-2.4)$ & 0.155 \\
\hline Concerns about working environment & $1.6(0.9-2.7)$ & 0.058 & $1.5(0.9-2.4)$ & 0.107 \\
\hline Perceptions about workplace support & $0.5(0.2-0.9)$ & 0.037 & $1.0(0.5-2)$ & 0.934 \\
\hline Perceptions about social connectedness & $0.3(0.1-0.6)$ & 0.001 & $0.6(0.3-1.2)$ & 0.173 \\
\hline
\end{tabular}

\section{Discussion}

Our study found (1) a significant improvement in anxiety scores amongst all ED HCWs and (2) a significant worsening in depression scores amongst ED doctors over a one-year period. Significantly higher odds of depression and anxiety were associated with HCWs who were $\geq 41$ years old, living with elderly, having concerns about infection risk and their workload. Significantly lower odds of depression and anxiety were associated with HCWs living with young children and those with better perception about workplace support and social connectedness.

It has been reported that at least one in every five HCWs suffers from depression and/or anxiety [15]. Our study, in line with a longitudinal analysis study carried out in Japan [16], showed that poor MHOs amongst HCWs were generally sustained during and between repeated outbreaks. Possible reasons for this could be that HCWs have to remain on guard against unexpected contacts, face daily infection risk whilst at work, incur transmission risk to their loved ones and increased workload [17-19].

Interestingly, another population group that has demonstrated similar poor MHOs as HCWs during this COVID-19 pandemic are college students. A large meta-analysis [20] consisting of 27 studies with 90,879 college students indicated a prevalence of $31.2 \%$ in depression and $39.4 \%$ in anxiety, with females having higher depression and anxiety than males.

\subsection{Overall Reduced Anxiety in HCWs}

Similar with other COVID-19 studies, including that on Belgian ICU nurses [10] over a two-month period and on Chinese HCWs over a one-month period [21], anxiety levels in HCWs, even though still high, showed a declining trend over time during a pandemic. However, evidence for this downtrend has been inconsistent $[5,9,22]$. One of the reasons for our higher baseline anxiety level could be that our 2020 survey was carried out just as we were exiting a 'circuit breaker' (national lock-down), causing anxiety scores to be 
high. This increased anxiety pattern during a quarantine was further demonstrated by a longitudinal study [23] on an Italian population at three time points over a month. The drop in median anxiety score in 2021 could be further explained by the fact that the excluded group of $86 \mathrm{HCWs}$ in the 2020 cohort had worse anxiety. Within this excluded group, there were ED staff who had resigned and returned home to their families overseas (in our 2020 survey [12], HCWs with family overseas had poorer MHOs). Moreover, within the excluded group with worse anxiety in 2020 were HCWs temporarily deployed to our $\mathrm{ED}$, and they may not have been familiar with the ED protocols and infective measures at that time.

The odds of developing anxiety amongst our HCWs were significantly lower in those living with young children, which is contrary to other studies' findings [24,25]. This is an interesting finding as just prior to this study, there was a surge in other COVID-19 variants and infection risk amongst children had started to climb. A possible hypothesis would be at the time of the survey, case rates in children in our country were extremely low, and we had no fatalities in children.

Overall, the reduction in anxiety score in 2021 could be that HCWs now have better understanding of the pathophysiology and mode of transmission of the virus, that they may have familiarised themselves with the infective measure routines at work, e.g., wearing of PPE and PAPR, and have adapted socially with wearing surgical masks in public areas and social distancing [6]. Furthermore, HCWs may have higher confidence in the government over the year-clear national guidelines and infective measures had been issued, the government's efficiency in ringfencing intermittent smaller outbreaks, the rapid roll-out of vaccination programmes including for teenagers more than 12 years of age and our relatively low daily case numbers and deaths compared to other countries.

\subsection{Increased Depression in Doctors}

In the majority of other COVID-19 studies, including our first survey in 2020 [12], nurses were shown to have worse depression compared to doctors [3,26-29]. Reasons cited have been that nurses have closer more frequent contact with patients and worked longer hours than usual $[26,27,29]$. Interestingly, our cohort of matched doctors had significantly worse depression in 2021 compared to 2020, and their overall depression score in 2021 became worse than our nursing staff's. One study which had similar outcome to ours was a Chinese cross-sectional study [17] carried out in 4 hospitals which showed that doctors had higher odds of developing moderate or severe depression (AOR 2.11 (0.96-4.64)) compared to nurses (AOR 1.66 (0.85-3.24)). Possible reasons for the worsening depression amongst our doctors could be due to the nature of their roles compared to nurses-the pressure and stress in assessing and diagnosing patients whilst being on constant guard for possible unexpected COVID-19 infection may have led to burnout [30].

Burnout is described as a state of physical, emotional and mental exhaustion that results from long-term involvement in work situations that are emotionally demanding [31]. Multiple studies have shown a reciprocal relationship between burnout and depressive symptoms. These include (1) a Portuguese cross-sectional study [32] amongst 2008 HCWs showing that higher levels of depression were significantly associated with increased levels of burnout and (2) a Finnish person-centred approach longitudinal study [33] amongst dentists over a seven-year period demonstrating that burnout and depressive symptoms clustered and developed in tandem at similar levels. It has also been widely reported that nurses experience primary and secondary traumatic stress, compassion fatigue and burnout during this COVID-19 pandemic, such as in this Chinese study [34]. However, another Spanish study [35] reported that physicians actually have higher compassion fatigue and burnout scores compared to nurses, demonstrating that both parties are likely equally vulnerable to emotional desensitization.

In a more local context, three recent Singaporean studies on HCWs also revealed that doctors were less likely to seek help for their mental health over concerns that making their struggles public may affect their licence to practice [36]. We postulate that the early signs 
of burnout were not well addressed in the doctor group at the start of the pandemic last year. Coupled with the inability to openly share of their struggles, these factors might have led to worsening depression scores in 2021. Because our survey was anonymous, it was easier for the doctors to report their feelings factually without the fear of being stigmatised or deemed unsafe to practice. This study's finding of deteriorating depression amongst our doctors is crucial as this could affect our doctors' cognitive function, precision, task performance and could have further physical ramifications.

\subsection{Increased Depression and Demographic Characteristics}

In our current study, HCWs $\geq 41$ years old had higher odds of developing depression. This is an interesting finding because population and healthcare studies [37,38] had shown that younger adults were associated with poorer MHOs during this COVID-19 pandemic. It was further explained that older adults' resilience was less influenced by stressful events, that younger adults may be more worried about losing their jobs and that younger adults may be overloaded with false information on social media. In line with our results, Yildirim et al. [39] and Pan et al. [40] had shown that older HCWs were associated with poorer MHOs. This could be that older HCWs felt more vulnerable physically (in terms of infection risk, morbidity and mortality) [38], may be worried about infecting their families and may feel more exhausted with the increased workload [41]. Another vulnerable subgroup of HCWs in our study were those living with elderly family member(s) - a subgroup with poorer MHOs which has also been demonstrated in other COVID-19 studies [4]. As previously explored in our first study [12], this subgroup of HCWs may have additional stressors with caregiving itself and fear of infecting their elderly loved ones at home.

\subsection{Increased Depression and Concerns about Workload}

Our HCWs with concerns about workload, specifically with concerns about lack of manpower in the fever area and spending longer hours at work, had higher odds of developing depression. Mo et al. [42] found that increased working time per week and work intensity were risk factors for poorer MHOs. The prolonged use of PPE was also shown to result in tension, fatigue and burnout. The increased workload in our cohort could be explained by Singapore's first hospital cluster outbreak which happened just prior to the 2021 study. That hospital was subsequently shut to ringfence the situation, and patients were re-directed to other nearby hospitals including this study's ED. We saw a surge in our ED's patient load, longer ED waiting times and increased bed blocks. Furthermore, to reduce infection risks between hospitals, locum HCWs who previously could move between different EDs to work could only work in one hospital, which also led to a shortage of our manpower.

\subsection{COVID-19 Vaccination}

Despite the high COVID-19 vaccination rate $(91.3 \%)$ in our 2021 cohort, there was no association between vaccination status and depression or anxiety. At the time of our study, there was no published studies looking into the association between COVID-19 vaccination and MHOs of ED HCWs. There was still no known long-term efficacy or safety profile of the vaccines, and these uncertainties could have contributed to why vaccination status had no association with improvement of MHOs.

\subsection{Strengths and Limitations}

To our best knowledge, this is the first longitudinal study carried out in frontline ED HCWs in Asia to assess the changes in depression and anxiety during this protracted COVID-19 pandemic. This study's longitudinal design is crucial in aiding healthcare systems to identify potential modifiable workplace factors associated with poorer MHOs over time. Furthermore, a validated assessment tool to measure depression and anxiety levels was used, and both cohorts of the study had high response rates and low numbers 
of missing data. The findings in our study emphasize the importance and need to develop psychological interventions to promote post-traumatic growth amongst our frontline ED HCWs.

Limitations of this study include it being a single-centre study carried out in one department which may limit the study's generalizability to other healthcare settings, and that socioeconomic factors, which may be confounders, had not been collected. The selfreport nature of depression and anxiety under the DASS-21 scale, rather than a clinicianfacilitated assessment, could also introduce bias to the results $[43,44]$.

\section{Conclusions}

In summary, our longitudinal study showed that frontline ED HCWs continued to have overall poor depression and anxiety scores despite intermittent bouts of the situation being more controlled over the one-year period. There was improvement in anxiety scores amongst all ED HCWs and worsening depression scores amongst ED doctors. Factors associated with depression and anxiety were those $\geq 41$ years old, living with elderly, with concerns about infection risk and workload. HCWs living with young children and those who perceive better workplace support and social connectedness were identified as protective factors.

The implications of this longitudinal study are that firstly, we need to recognise that effects of psychological distress inflicted by a pandemic are long-standing. From an occupational health standpoint, workplace mental health interventions cannot be sporadic, but should be regular and sustained. HCWs should continue to receive updated information about infection protocols and risk management, as well as redistribution of workload from the fever area for those most affected.

Secondly, this longitudinal study builds on the understanding that certain factors associated with depression and anxiety are non-modifiable, such as those older than 40 years of age and those living with the elderly. Gaining a better understanding of how these groups connect to fellow beings, whether through social media or lack thereof, will allow us to develop mental health programs targeted towards them. The results of the survey will also be shared with department heads and nursing leads so that they can better identify the at-risk groups to attend hospital-wide wellness initiatives.

Author Contributions: F.T., K.A.R. and D.M. were involved in the concept and design of the study. F.T. obtained research funding. F.T., K.A.R., D.M., H.N.N. and E.S. supervised the conduct of the study and data collection. L.G. and J.A.D.M. managed the data including quality control. F.T., K.A.R., L.G., D.M. and J.A.D.M. provided advice on study design, methodology and statistical support. L.G. and J.A.D.M. analysed the data. F.T. and K.A.R. drafted the manuscript, and all authors contributed substantially to its revision. F.T. takes overall responsibility for the paper. All authors have read and agreed to the published version of the manuscript.

Funding: This study is supported by the Alexandra Health Fund Ltd. through the Alexandra Health Enabling Grant (AHEG), grant number AHEG2105.

Institutional Review Board Statement: The study was conducted according to the guidelines of the Declaration of Helsinki, and approved by the Institutional Review Board (or Ethics Committee) of National Healthcare Group (DSRB 2020/00653 and 2021/00336; and date of approval on 27 May 2020 and 12 May 2021 respectively).

Informed Consent Statement: Written consent was obtained from all subjects involved in the study.

Data Availability Statement: The individual datasets collected and analysed will not be publicly made available due to privacy and confidentiality reasons. Data presented in this study is available upon request from the corresponding author.

Conflicts of Interest: The authors declare no conflict of interest. The funders had no role in the design of the study; in the collection, analyses, or interpretation of data; in the writing of the manuscript, or in the decision to publish the results. 


\section{Appendix A}

Table A1. Timeline of main changes in Singapore through the one-year period of the survey studies (1 June 2020 to 16 June 2021) [45].

\begin{tabular}{|c|c|}
\hline 1 June 20 & 408 cases. Final day of 8-week circuit breaker (national lock-down). \\
\hline 2 June 20 & $\begin{array}{l}544 \text { cases. Phase 1: Compulsory to wear face masks in public areas, } \\
\text { Pre-schools/schools/institutions to re-open in phases, People } \\
\text { encouraged to work from home, Only allowed to visit } \\
\text { parents/grandparents from a different household. }\end{array}$ \\
\hline 9 June 20 & 218 cases. \\
\hline 19 June 20 & $\begin{array}{l}142 \text { cases. Phase } 2 \text { : Maximum groups of } 5 \text { with safe distancing of } \\
1 \text { metre in public areas, Reopening of park, sports facilities and } \\
\text { cafes/restaurants. }\end{array}$ \\
\hline 28 December 20 & $\begin{array}{l}5 \text { cases ( } 0 \text { local cases). Phase 3: Maximum groups of } 8 \text { allowed in public } \\
\text { areas. }\end{array}$ \\
\hline 11 January 21 & $\begin{array}{l}22 \text { cases (0 local cases). COVID-19 vaccine (Pfizer) offered to all HCWs } \\
\text { in KTPH. }\end{array}$ \\
\hline 10 March 21 & $\begin{array}{l}10 \text { cases ( } 0 \text { local cases). COVID-19 vaccination offered to residents } \\
60 \text { years old and above nationally. }\end{array}$ \\
\hline 25 March 21 & $\begin{array}{l}17 \text { cases ( } 0 \text { local cases). COVID-19 vaccination offered to residents } \\
45-59 \text { years old nationally. }\end{array}$ \\
\hline 29 April 21 & $\begin{array}{l}35 \text { cases (16 local cases-highest number over past } 9 \text { months). } \\
\text { First COVID-19 cluster involving a hospital. N95s to be used even in } \\
\text { clean areas in our hospital instead of surgical masks. }\end{array}$ \\
\hline 4 May 21 & $\begin{array}{l}17 \text { cases ( } 5 \text { local cases). Affected hospital cluster was shut-all cases } \\
\text { diverted to other hospitals including KTPH. }\end{array}$ \\
\hline 5 May 21 & $\begin{array}{l}16 \text { cases ( } 1 \text { local case). All healthcare workers to be swabbed every } \\
1-2 \text { weeks. }\end{array}$ \\
\hline 8 May 21 & $\begin{array}{l}20 \text { cases ( } 7 \text { local cases). Reduction of public groups from } 8 \text { to } 5 \text { people, } \\
\text { Cessation of all indoors physical activities. }\end{array}$ \\
\hline 14 May 21 & $\begin{array}{l}52 \text { cases ( } 24 \text { local cases). Emergence of multiple new clusters including } \\
\text { a children tuition centre and another hospital. }\end{array}$ \\
\hline 16 May 21 & $\begin{array}{l}49 \text { new cases ( } 38 \text { local cases). Social gatherings limited from } 5 \text { to } \\
2 \text { people, Defaulted to work from home, No dine-ins in public areas. }\end{array}$ \\
\hline 19 May 21 & $\begin{array}{l}38 \text { cases ( } 34 \text { local cases). All institutions shut as COVID-19 affecting a } \\
\text { high proportion of children. COVID- } 19 \text { vaccination offered to residents } \\
40-44 \text { years old nationally. }\end{array}$ \\
\hline 1st June 21 & $\begin{array}{l}18 \text { cases ( } 15 \text { local cases). Students } \geq 12 \text { years old offered COVID-19 } \\
\text { vaccination nationally. }\end{array}$ \\
\hline 11 June 21 & $\begin{array}{l}9 \text { cases ( } 3 \text { local cases). Vaccination offered to residents } 12-39 \text { years old } \\
\text { nationally. }\end{array}$ \\
\hline 14 June 21 & $\begin{array}{l}25 \text { cases (19 local cases). Gatherings up to } 5 \text { people again, no dine-ins } \\
\text { till } 21 \text { June } 2021 .\end{array}$ \\
\hline 16 June 21 & 24 cases (19 local cases). \\
\hline
\end{tabular}




\section{Appendix B}

Study Protocol: Longitudinal study: Factors associated with Mental Health Outcomes in Frontline Emergency Department Healthcare Workers of the COVID-19 Pandemic

Date: Last 4 digits of mobile number:

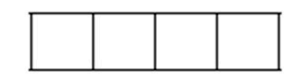

\section{A. Demographic information}

\begin{tabular}{|c|c|c|c|}
\hline A1 & Gender & 1. Fem & 2. Male \\
\hline \multirow[t]{3}{*}{$A 2$} & Age (in years) & 1. $21-3$ & 4. $51-60$ \\
\hline & & 2. $31-4$ & 5. 61 and older \\
\hline & & 3. $41-5$ & \\
\hline \multirow[t]{6}{*}{$A 3$} & Ethnicity & 1. Chir & \\
\hline & & 2. Mal & \\
\hline & & 3. Indi & \\
\hline & & 4. Filip & \\
\hline & & 5. Cau & \\
\hline & & 6. Oth & cify) \\
\hline \multirow[t]{4}{*}{ A4 } & Marital status & 1. Sing & \\
\hline & & 2. Mar & \\
\hline & & 3. Sep & Divorced \\
\hline & & 4. Wid & \\
\hline \multirow[t]{4}{*}{ A5a } & Occupation & \multirow{4}{*}{\multicolumn{2}{|c|}{$\begin{array}{l}\text { 1. Senior Doctor-defined as Dr on Senior roster } \\
\text { 2. Junior Doctor-defined as Dr on the Junior roster } \\
\text { 3. Nurse } \\
\text { 4. Healthcare Assistant }\end{array}$}} \\
\hline & & & \\
\hline & & & \\
\hline & & & \\
\hline A5b & Number of years in current occupation & & \\
\hline A6 & $\begin{array}{l}\text { Past medical history of chronic diseases (e.g., } \\
\text { Hypertension, Diabetes) }\end{array}$ & 1. Yes & 2. No \\
\hline A7 & $\begin{array}{l}\text { Past psychiatric history (e.g., depression, } \\
\text { anxiety and panic disorders) }\end{array}$ & 1. Yes & 2. No \\
\hline A8 & I live with young children (<12 y.o.) at home & 1. Yes & 2. No \\
\hline A9 & I live with elderly (>65 y.o.) at home & 1. Yes & 2. No \\
\hline A10 & I live alone & 1. Yes & 2. No \\
\hline A11 & I practice a religion & 1. Yes & 2. No \\
\hline A12 & $\begin{array}{l}\text { I have a family member or close friend who } \\
\text { has contracted COVID-19 during this outbreak }\end{array}$ & 1. Yes & 2. No \\
\hline A13 & $\begin{array}{l}\text { I have received the COVID-19 vaccine } \\
\text { (includes one or two doses of vaccine) }\end{array}$ & 1. Yes & 2. No \\
\hline
\end{tabular}

Figure A1. Cont. 
B. Please read each statement and circle a number $0,1,2$ or 3 which indicates how much the statement applied to you over the past week. There are no right or wrong answers. Do not spend too much time on any statement.

The rating scale is as follows:

0 Did not apply to me at all

1 Applied to me to some degree, or some of the time

2 Applied to me to a considerable degree, or a good part of time

3 Applied to me very much, or most of the time

\begin{tabular}{|c|c|c|c|c|c|}
\hline B1 & I found it hard to wind down & 0 & 1 & 2 & 3 \\
\hline B2 & I was aware of dryness of my mouth & 0 & 1 & 2 & 3 \\
\hline B3 & I couldn't seem to experience any positive feeling at all & 0 & 1 & 2 & 3 \\
\hline B4 & $\begin{array}{l}\text { I experienced breathing difficulty (e.g., excessively rapid breathing, } \\
\text { breathlessness in the absence of physical exertion) }\end{array}$ & 0 & 1 & 2 & 3 \\
\hline B5 & I found it difficult to work up the initiative to do things & 0 & 1 & 2 & 3 \\
\hline B6 & I tended to over-react to situations & 0 & 1 & 2 & 3 \\
\hline B7 & I experienced trembling (e.g., in the hands) & 0 & 1 & 2 & 3 \\
\hline B8 & I felt that I was using a lot of nervous energy & 0 & 1 & 2 & 3 \\
\hline B9 & $\begin{array}{l}\text { I was worried about situations in which I might panic and make a fool of } \\
\text { myself }\end{array}$ & 0 & 1 & 2 & 3 \\
\hline B10 & I felt that I had nothing to look forward to & 0 & 1 & 2 & 3 \\
\hline B11 & I found myself getting agitated & 0 & 1 & 2 & 3 \\
\hline B12 & I found it difficult to relax & 0 & 1 & 2 & 3 \\
\hline B13 & I felt down-hearted and blue & 0 & 1 & 2 & 3 \\
\hline B14 & $\begin{array}{l}\text { I was intolerant of anything that kept me from getting on with what I was } \\
\text { doing }\end{array}$ & 0 & 1 & 2 & 3 \\
\hline B15 & I felt I was close to panic & 0 & 1 & 2 & 3 \\
\hline B16 & I was unable to become enthusiastic about anything & 0 & 1 & 2 & 3 \\
\hline B17 & I felt I wasn't worth much as a person & 0 & 1 & 2 & 3 \\
\hline B18 & I felt that I was rather touchy & 0 & 1 & 2 & 3 \\
\hline B19 & $\begin{array}{l}\text { I was aware of the action of my heart in the absence of physical exertion } \\
\text { (e.g., sense of heart rate increase, heart missing a beat) }\end{array}$ & 0 & 1 & 2 & 3 \\
\hline B20 & I felt scared without any good reason & 0 & 1 & 2 & 3 \\
\hline B21 & I felt that life was meaningless & 0 & 1 & 2 & 3 \\
\hline
\end{tabular}

Figure A1. Cont. 
C. Below is a list of difficulties people sometimes have after stressful life events. Please read each item, and then indicate how distressing each difficulty has been for you for the past 7 days with respect to COVID-19. How much have you been distressed or bothered by these difficulties?

\begin{tabular}{|c|c|c|c|c|c|c|}
\hline & & Not At All & A Little Bit & Moderately & Quite A Bit & Extremely \\
\hline C1 & $\begin{array}{l}\text { Any reminder brought back feelings } \\
\text { about it }\end{array}$ & 0 & 1 & 2 & 3 & 4 \\
\hline $\mathrm{C2}$ & I had trouble staying asleep & 0 & 1 & 2 & 3 & 4 \\
\hline C3 & $\begin{array}{l}\text { Other things kept making me think about } \\
\text { it }\end{array}$ & 0 & 1 & 2 & 3 & 4 \\
\hline C4 & I felt irritable and angry & 0 & 1 & 2 & 3 & 4 \\
\hline C5 & $\begin{array}{l}\text { I avoided letting myself get upset when I } \\
\text { thought about it or was reminded of it }\end{array}$ & 0 & 1 & 2 & 3 & 4 \\
\hline C6 & I thought about it when I didn't mean to & 0 & 1 & 2 & 3 & 4 \\
\hline C7 & $\begin{array}{l}\text { I felt as if it hadn't happened or wasn't } \\
\text { real }\end{array}$ & 0 & 1 & 2 & 3 & 4 \\
\hline C8 & I stayed away from reminders of it & 0 & 1 & 2 & 3 & 4 \\
\hline C9 & Pictures about it popped into my mind & 0 & 1 & 2 & 3 & 4 \\
\hline C10 & I was jumpy and easily startled & 0 & 1 & 2 & 3 & 4 \\
\hline C11 & I tried not to think about it & 0 & 1 & 2 & 3 & 4 \\
\hline C12 & $\begin{array}{l}\text { I was aware that I still had a lot of } \\
\text { feelings about it, but I didn't deal with } \\
\text { them }\end{array}$ & 0 & 1 & 2 & 3 & 4 \\
\hline C13 & My feelings about it were kind of numb & 0 & 1 & 2 & 3 & 4 \\
\hline C14 & $\begin{array}{l}\text { I found myself acting or feeling like I was } \\
\text { back at that time }\end{array}$ & 0 & 1 & 2 & 3 & 4 \\
\hline C15 & I had trouble falling asleep & 0 & 1 & 2 & 3 & 4 \\
\hline C16 & I had waves of strong feelings about it & 0 & 1 & 2 & 3 & 4 \\
\hline C17 & I tried to remove it from my memory & 0 & 1 & 2 & 3 & 4 \\
\hline C18 & I had trouble concentrating & 0 & 1 & 2 & 3 & 4 \\
\hline C19 & $\begin{array}{l}\text { Reminders of it caused me to have } \\
\text { physical reactions such as sweating, } \\
\text { trouble breathing, nausea, or a pounding } \\
\text { heart }\end{array}$ & 0 & 1 & 2 & 3 & 4 \\
\hline $\mathrm{C20}$ & I had dreams about it & 0 & 1 & 2 & 3 & 4 \\
\hline C21 & I felt watchful and on-guard & 0 & 1 & 2 & 3 & 4 \\
\hline $\mathrm{C} 22$ & I tried not to talk about it & 0 & 1 & 2 & 3 & 4 \\
\hline
\end{tabular}

Figure A1. Cont. 


\section{Concerns regarding COVID-19}

Please indicate how much you agree or disagree with the following statements based on your experience over the past year.

\begin{tabular}{|c|c|c|c|c|c|c|c|}
\hline & & $\begin{array}{l}\text { Strongly } \\
\text { Disagree }\end{array}$ & Disagree & $\begin{array}{l}\text { Not Sure } \\
\text { But } \\
\text { Probably } \\
\text { Disagree }\end{array}$ & $\begin{array}{l}\text { Not Sure } \\
\text { But } \\
\text { Probably } \\
\text { Agree }\end{array}$ & Agree & $\begin{array}{l}\text { Strongly } \\
\text { Agree }\end{array}$ \\
\hline \multirow[t]{6}{*}{ D1 } & $\begin{array}{l}\text { I find the following components of PPE } \\
\text { uncomfortable to wear: (Circle for those } \\
\text { components you wear at work) }\end{array}$ & & & & & & \\
\hline & Mask (N95) & 1 & 2 & 3 & 4 & 5 & 6 \\
\hline & Goggles / Face shield & 1 & 2 & 3 & 4 & 5 & 6 \\
\hline & Gloves & 1 & 2 & 3 & 4 & 5 & 6 \\
\hline & Gown & 1 & 2 & 3 & 4 & 5 & 6 \\
\hline & PAPR & 1 & 2 & 3 & 4 & 5 & 6 \\
\hline D2 & $\begin{array}{l}\text { Wearing PPE prevents me from doing } \\
\text { certain procedures properly }\end{array}$ & 1 & 2 & 3 & 4 & 5 & 6 \\
\hline D3 & $\begin{array}{l}\text { It is difficult to communicate properly } \\
\text { with patients while wearing PPE }\end{array}$ & 1 & 2 & 3 & 4 & 5 & 6 \\
\hline D4 & The fever area is too hot to work in & 1 & 2 & 3 & 4 & 5 & 6 \\
\hline D5 & $\begin{array}{l}\text { There is a lack of manpower in the fever } \\
\text { area }\end{array}$ & 1 & 2 & 3 & 4 & 5 & 6 \\
\hline D6 & $\begin{array}{l}\text { I feel there is an increased risk of } \\
\text { contracting COVID-19 by working in the } \\
\text { fever area }\end{array}$ & 1 & 2 & 3 & 4 & 5 & 6 \\
\hline D7 & $\begin{array}{l}\text { There is an increase in workload since the } \\
\text { outbreak started }\end{array}$ & 1 & 2 & 3 & 4 & 5 & 6 \\
\hline D8 & $\begin{array}{l}\text { I spend longer hours at work since the } \\
\text { outbreak started }\end{array}$ & 1 & 2 & 3 & 4 & 5 & 6 \\
\hline D9 & $\begin{array}{l}\text { I am afraid of being infected with COVID- } \\
19 \text { while at work }\end{array}$ & 1 & 2 & 3 & 4 & 5 & 6 \\
\hline D10 & $\begin{array}{l}\text { My job puts me at high risk of exposure } \\
\text { to COVID-19 }\end{array}$ & 1 & 2 & 3 & 4 & 5 & 6 \\
\hline D11 & $\begin{array}{l}\text { The risk I am exposed to at work is } \\
\text { acceptable }\end{array}$ & 1 & 2 & 3 & 4 & 5 & 6 \\
\hline D12 & $\begin{array}{l}\text { Work has been more tiring since the } \\
\text { outbreak started }\end{array}$ & 1 & 2 & 3 & 4 & 5 & 6 \\
\hline D13 & $\begin{array}{l}\text { I have managed to get enough breaks } \\
\text { whilst on my shifts }\end{array}$ & 1 & 2 & 3 & 4 & 5 & 6 \\
\hline D14 & $\begin{array}{l}\text { I am confident my employer would look } \\
\text { after my needs if I fall ill with COVID-19 }\end{array}$ & 1 & 2 & 3 & 4 & 5 & 6 \\
\hline
\end{tabular}

Figure A1. Cont. 


\begin{tabular}{|c|c|c|c|c|c|c|c|}
\hline D15 & $\begin{array}{l}\text { I am satisfied with the hospital response } \\
\text { to the outbreak }\end{array}$ & 1 & 2 & 3 & 4 & 5 & 6 \\
\hline D16 & $\begin{array}{l}\text { I receive clear communication of } \\
\text { outbreak directives from my superiors }\end{array}$ & 1 & 2 & 3 & 4 & 5 & 6 \\
\hline D17 & People respect the work that I do & 1 & 2 & 3 & 4 & 5 & 6 \\
\hline D18 & $\begin{array}{l}\text { People close to me are worried about } \\
\text { getting infected by me }\end{array}$ & 1 & 2 & 3 & 4 & 5 & 6 \\
\hline D19 & $\begin{array}{l}\text { I am worried about infecting my loved } \\
\text { ones because of my job (Circle only if you } \\
\text { live or interact with loved ones locally) }\end{array}$ & 1 & 2 & 3 & 4 & 5 & 6 \\
\hline D20 & $\begin{array}{l}\text { I take additional precautions when } \\
\text { interacting with my loved ones during } \\
\text { this period (Circle only if applicable) }\end{array}$ & 1 & 2 & 3 & 4 & 5 & 6 \\
\hline D21 & $\begin{array}{l}\text { I am frustrated about not being able to } \\
\text { visit my family living abroad (Circle only if } \\
\text { applicable) }\end{array}$ & 1 & 2 & 3 & 4 & 5 & 6 \\
\hline \multicolumn{8}{|c|}{ E. Coping strategies } \\
\hline \multicolumn{8}{|c|}{$\begin{array}{l}\text { Please indicate how much you agree or disagree with the following statements based on your experience } \\
\text { over the past year. }\end{array}$} \\
\hline & & $\begin{array}{l}\text { Strongly } \\
\text { Disagree }\end{array}$ & Disagree & $\begin{array}{l}\text { Not Sure } \\
\text { But } \\
\text { Probably } \\
\text { Disagree }\end{array}$ & $\begin{array}{l}\text { Not Sure } \\
\text { But } \\
\text { Probably } \\
\text { Agree }\end{array}$ & Agree & $\begin{array}{l}\text { Strongly } \\
\text { Agree }\end{array}$ \\
\hline \multirow[t]{5}{*}{ E1 } & I get adequate support from my: & & & & & & \\
\hline & Family & 1 & 2 & 3 & 4 & 5 & 6 \\
\hline & Friends & 1 & 2 & 3 & 4 & 5 & 6 \\
\hline & Supervisors & 1 & 2 & 3 & 4 & 5 & 6 \\
\hline & Colleagues & 1 & 2 & 3 & 4 & 5 & 6 \\
\hline E2 & My religion helps me cope with stress & 1 & 2 & 3 & 4 & 5 & 6 \\
\hline E3 & $\begin{array}{l}\text { Being able to see my colleagues at work } \\
\text { helps to decrease feelings of social } \\
\text { isolation }\end{array}$ & 1 & 2 & 3 & 4 & 5 & 6 \\
\hline E4 & Exercise helps me cope with stress & 1 & 2 & 3 & 4 & 5 & 6 \\
\hline
\end{tabular}

Figure A1. COVID-19 survey questionnaire for 2021. 


\section{Appendix C}

\begin{tabular}{|l|}
\hline \multicolumn{1}{|c|}{ Infection Risk } \\
$\alpha=0.70$ (2020), 0.74 (2021) \\
\hline - D6: I feel there is an \\
increased risk \\
contracting COVID-19 \\
by working in the fever \\
area \\
- D9: I am afraid of being \\
infected with COVID-19 \\
while at work \\
-D10: My job puts me at \\
high risk of exposure to \\
COVID-19 \\
-D11: The risk I am \\
exposed to at work is \\
acceptable \\
-D18: People close to \\
me are worried about \\
getting infected by me \\
-D19: I am worried \\
about infecting my \\
loved once because of \\
my job
\end{tabular}

\begin{tabular}{|l|}
\hline $\begin{array}{c}\text { Working Environment } \\
\alpha=0.70 \text { (2020), 0.83 (2021) }\end{array}$ \\
\hline - D1a: I find Mask (N95) \\
uncomfortable to wear \\
- D1b: I find Goggles / \\
Face shield \\
uncomfortable to wear \\
- D1c: I find Gloves \\
uncomfortable to wear \\
- D1d: I find Gown \\
uncomfortable to wear \\
- D1e: I find PAPR \\
uncomfortable to wear \\
- D2: Wearing PPE \\
prevents me from doing \\
certain procedures \\
properly \\
- D3: It is difficult to \\
communicate properly \\
with patients while \\
wearing PPE \\
- D4: The fever area is \\
too hot to work in
\end{tabular}

\begin{tabular}{|l|}
\hline \multicolumn{1}{|c|}{ Worklod } \\
$\alpha=0.75(2020), 0.75$ (2021) \\
\hline -D5: There is a lack of \\
manpower in the fever \\
area \\
-D7: There is an \\
increase in workload \\
since the outbreak \\
started \\
-D8: I spend longer \\
hours at work since the \\
outbreak started \\
-D12: Work has been \\
more tiring since the \\
outbreak started
\end{tabular}
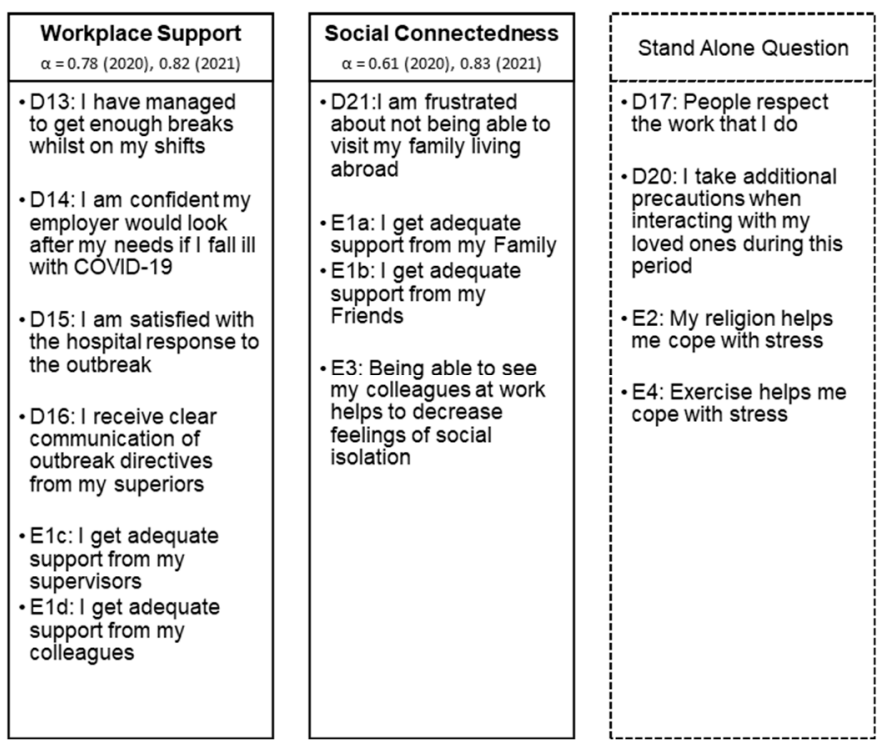

Figure A2. Questions on participants' concerns and perceptions were categorised based on content relevance shown below for data analysis with listed factor analysis (Cronbach's alpha, $\alpha$ ).

\section{Appendix D}

Table A2. Association between individual questions in 'Workload', 'Infection risk', 'Workplace support' and 'Social connectedness' categories with the relevant MHOs (univariate analysis).

\begin{tabular}{lcc}
\multicolumn{1}{c}{ Questions } & Depression & Anxiety \\
\cline { 2 - 3 } & $p$-Value & $p$-Value \\
\hline Workload (Higher odds of Depression) & & \\
D5: There is a lack of manpower in the fever area & 0.002 & \\
D7: There is an increase in workload since the outbreak started & 0.093 & \\
D8: I spend longer hours at work since the outbreak started & 0.010 & \\
D12: Work has been more tiring since the outbreak started & 0.167 & \\
\hline Infection risk (Higher odds of Anxiety) & & 0.545 \\
D6: I feel there is an increased risk of contracting COVID-19 by working in the fever area & & 0.879 \\
D9: I am afraid of being infected with COVID-19 while at work & & 0.389 \\
D10: My job puts me at high risk of exposure to COVID-19 & & 0.657 \\
D11: The risk I am exposed to at work is acceptable & & 1.00 \\
D18: People close to me are worried about getting infected by me & \\
D19: I am worried about infecting my loved once because of my job & & \\
\hline Workplace support (Lower odds of Depression) & & 0.074 \\
D13: I have managed to get enough breaks whilst on my shifts & $<0.001$ & \\
D14: I am confident my employer would look after my needs if I fall ill withCOVID-19 & 0.002 & \\
D15: I am satisfied with the hospital response to the outbreak & $<.031$ & \\
D16: I receive clear communication of outbreak directives from my superiors & 0.001 & \\
E1c: I get adequate support from my supervisors & \\
E1d: I get adequate support from my colleagues & & \\
\hline Social connectedness (Lower odds of Depression) & 0.806 & \\
D21:I am frustrated about not being able to visit my family living abroad & \\
E1a: I get adequate support from my Family & & \\
E1b: I get adequate support from my Friends & & \\
E3: Being able to see my colleagues at work helps to decrease feelings of social isolation & 0.006 & \\
\hline
\end{tabular}




\section{Appendix E}

Table A3. Comparison of the $86 \mathrm{HCWs}$ who were excluded from the 2020 cohort (19 ED staff resigned, 22 temporarily deployed staff to ED and 45 responses unable to be matched to 2 nd survey) with the 241 HCWs who were included.

\begin{tabular}{lccc}
\hline & $\begin{array}{c}\text { Excluded in 2020 } \\
(\mathbf{n}=\mathbf{8 6})\end{array}$ & $\begin{array}{c}\text { Included in 2020 } \\
(\mathbf{n}=\mathbf{2 4 1})\end{array}$ & $p$-Value \\
\hline Depression & & & \\
Yes (n,\%) & $29(33.7)$ & $61(25.3)$ & 0.134 \\
No (n,\%) & $57(66.3)$ & $180(74.7)$ & 0.026 \\
Median (IQR) & $3(1-6)$ & $2(0-5)$ & - \\
Mean \pm SD & $4.05 \pm 3.89$ & $3.05 \pm 3.50$ & \\
\hline Anxiety & $38(44.2)$ & & 0.024 \\
Yes (n,\%) & $48(55.8)$ & $74(30.7)$ & 0.038 \\
No (n,\%) & $3(1-6)$ & $167(69.3)$ & - \\
Median (IQR) & $3.71 \pm 3.49$ & $2(0-4)$ & \\
Mean \pm SD & & $2.86 \pm 3.18$ & \\
\hline
\end{tabular}

\section{References}

1. Batra, K.; Singh, T.P.; Sharma, M.; Batra, R.; Schvaneveldt, N. Investigating the psychological impact of COVID-19 among healthcare workers: A meta-analysis. Int. J. Environ. Res. Public Health 2020, 17, 9096. [CrossRef]

2. Nguyen, L.H.; Drew, D.A.; Graham, M.S.; Joshi, A.D.; Guo, C.G.; Ma, W.; Mehta, R.S.; Warner, E.T.; Sikavi, D.R.; Lo, C.H.; et al. Risk of COVID-19 among front-line health-care workers and the general community: A prospective cohort study. Lancet Public Health 2020, 5, e475-e483. [CrossRef]

3. Shaukat, N.; Ali, D.M.; Razzak, J. Physical and mental health impacts of COVID-19 on healthcare workers: A scoping review. Int. J. Emerg. Med. 2020, 13, 40. [CrossRef] [PubMed]

4. Muller, R.A.; Stensland, R.S.; van de Velde, R.S. The mental health impact of the covid-19 pandemic on healthcare workers, and interventions to help them: A rapid systematic review. Psychiatry Res. 2020, 1, 113441. [CrossRef]

5. Cai, Z.; Cui, Q.; Liu, Z.; Li, J.; Gong, X.; Liu, J.; Wan, Z.; Yuan, X.; Li, X.; Chen, C.; et al. Nurses endured high risks of psychological problems under the epidemic of COVID-19 in a longitudinal study in Wuhan China. J. Psychiatr. Res. 2020, 131, $132-137$. [CrossRef]

6. $\quad$ Chew, Q.H.; Chia, F.L.; Ng, W.K.; Lee, W.C.; Tan, P.L.; Wong, C.S.; Puah, S.H.; Shelat, V.G.; Seah, E.J.; Huey, C.W.; et al. Perceived Stress, Stigma, Traumatic Stress Levels and Coping Responses amongst Residents in Training across Multiple Specialties during COVID-19 Pandemic-A Longitudinal Study. Int. J. Environ. Res. Public Health 2020, 17, 6572. [CrossRef]

7. Kwong, A.S.; Pearson, R.M.; Adams, M.J.; Northstone, K.; Tilling, K.; Smith, D.; Fawns-Ritchie, C.; Bould, H.; Warne, N.; Zammit, S.; et al. Mental health during the COVID-19 pandemic in two longitudinal UK population cohorts. Br. J. Psychiatry 2020, 218, 334-343. [CrossRef]

8. González-Sanguino, C.; Ausín, B.; Castellanos, M.Á.; Saiz, J.; López-Gómez, A.; Ugidos, C.; Muñoz, M. Mental health consequences of the Coronavirus 2020 Pandemic (COVID-19) in Spain. A longitudinal study. Front. Psychiatry 2020, 11, 1256. [CrossRef] [PubMed]

9. Zhou, Y.; Ding, H.; Zhang, Y.; Zhang, B.; Guo, Y.; Cheung, T.; Hall, B.J.; Shi, T.; Xiang, Y.T.; Tang, Y. Prevalence of poor psychiatric status and sleep quality among frontline healthcare workers during and after the COVID-19 outbreak: A longitudinal study. Transl. Psychiatry 2021, 11, 223. [CrossRef]

10. Van Steenkiste, E.; Schoofs, J.; Gilis, S.; Messiaen, P. Mental health impact of COVID-19 in frontline healthcare workers in a Belgian Tertiary care hospital: A prospective longitudinal study. Acta Clin. Belg. 2021, 7, 1-8. [CrossRef] [PubMed]

11. Pietrzak, E.; Pullman, S.; Cotea, C.; Nasveld, P. Effects of deployment on health behaviours in military forces: A review of longitudinal studies. J. Mil. Veterans Health 2013, 21, 14-23.

12. Rao, A.K.; Th'ng, F.; Mak, C.C.M.; Neo, H.N.; Ubeynarayana, C.U.; Kumar, R.K.N.; Mao, D.R.H. Factors associated with Mental Health Outcomes in Emergency Department Healthcare Workers on the frontlines of the COVID-19 Pandemic. Singap. Med. J. Date Cit. 2021, in press. [CrossRef] [PubMed]

13. Verdolini, N.; Amoretti, S.; Montejo, L.; García-Rizo, C.; Hogg, B.; Mezquida, G.; Rabelo-da-Ponte, F.D.; Vallespir, C.; Radua, J.; Martinez-Aran, A.; et al. Resilience and mental health during the COVID-19 pandemic. J. Affect. Disord. 2021, 283, 156-164. [CrossRef] [PubMed]

14. Lovibond, S.H.; Lovibond, P.F. Manual for the Depression Anxiety Stress Scales, 2nd ed.; Psychology Foundation: Sydney, Australia, 1995; ISBN 7334-1423-7330. 
15. Pappa, S.; Ntella, V.; Giannakas, T.; Giannakoulis, V.G.; Papoutsi, E.; Katsaounou, P. Prevalence of depression, anxiety, and insomnia among healthcare workers during the COVID-19 pandemic: A systematic review and meta-analysis. Brain Behav. Immun. 2020, 88, 901-907. [CrossRef]

16. Sasaki, N.; Asaoka, H.; Kuroda, R.; Tsuno, K.; Imamura, K.; Kawakami, N. Sustained poor mental health among healthcare workers in COVID-19 pandemic: A longitudinal analysis of the four-wave panel survey over 8 months in Japan. J. Occup. Health 2021, 63, e12227. [CrossRef] [PubMed]

17. Wang, H.; Huang, D.; Huang, H.; Zhang, J.; Guo, L.; Liu, Y.; Ma, H.; Geng, Q. The psychological impact of COVID-19 pandemic on medical staff in Guangdong, China: A cross-sectional study. Psychol. Med. 2020. [CrossRef] [PubMed]

18. Ji, D.; Ji, Y.J.; Duan, X.Z.; Li, W.G.; Sun, Z.Q.; Song, X.A.; Meng, Y.H.; Tang, H.M.; Chu, F.; Niu, X.X.; et al. Prevalence of psychological symptoms among Ebola survivors and healthcare workers during the 2014-2015 Ebola outbreak in Sierra Leone: A cross-sectional study. Oncotarget 2017, 8, 12784. [CrossRef]

19. Mokhtari, R.; Moayedi, S.; Golitaleb, M. COVID-19 pandemic and health anxiety among nurses of intensive care units. Int. J. Ment. Health Nurs. 2020, 29, 1275. [CrossRef]

20. Batra, K.; Sharma, M.; Batra, R.; Singh, T.P.; Schvaneveldt, N. Assessing the psychological impact of COVID-19 among college students: An evidence of 15 countries. Healthcare 2021, 9, 222. [CrossRef]

21. Xu, J.; Xu, Q.H.; Wang, C.M.; Wang, J. Psychological status of surgical staff during the COVID-19 outbreak. Psychiatry Res. 2020, 288, 112955. [CrossRef] [PubMed]

22. Yuan, S.; Liao, Z.; Huang, H.; Jiang, B.; Zhang, X.; Wang, Y.; Zhao, M. Comparison of the indicators of psychological stress in the population of Hubei province and non-endemic provinces in China during two weeks during the coronavirus disease 2019 (COVID-19) outbreak in February 2020. Med. Sci. Monit. Int. Med. J. Exp. Clin. Res. 2020, 26, e923767-1.

23. Ruggieri, S.; Ingoglia, S.; Bonfanti, R.C.; Coco, G.L. The role of online social comparison as a protective factor for psychological wellbeing: A longitudinal study during the COVID-19 quarantine. Personal. Individ. Differ. 2021, 171, 110486. [CrossRef]

24. Pierce, M.; Hope, H.; Ford, T.; Hatch, S.; Hotopf, M.; John, A.; Kontopantelis, E.; Webb, R.; Wessely, S.; McManus, S.; et al. Mental health before and during the COVID-19 pandemic: A longitudinal probability sample survey of the UK population. Lancet Psychiatry 2020, 7, 883-892. [CrossRef]

25. Liu, D.; Baumeister, R.F.; Veilleux, J.C.; Chen, C.; Liu, W.; Yue, Y.; Zhang, S. Risk factors associated with mental illness in hospital discharged patients infected with COVID-19 in Wuhan, China. Psychiatry Res. 2020, 292, 113297. [CrossRef]

26. Pappa, S.; Sakkas, N.; Sakka, E. A Year in Review: Sleep Dysfunction and Psychological Distress in Healthcare Workers during the COVID-19 Pandemic. Sleep Med. 2021. [CrossRef]

27. Fteropoulli, T.; Kalavana, T.V.; Yiallourou, A.; Karaiskakis, M.; Koliou Mazeri, M.; Vryonides, S.; Hadjioannou, A.; Nikolopoulos, G.K. Beyond the physical risk: Psychosocial impact and coping in healthcare professionals during the COVID-19 pandemic. J. Clin. Nurs. 2021. [CrossRef] [PubMed]

28. De Kock, J.H.; Latham, H.A.; Leslie, S.J.; Grindle, M.; Munoz, S.A.; Ellis, L.; Polson, R.; O'Malley, C.M. A rapid review of the impact of COVID-19 on the mental health of healthcare workers: Implications for supporting psychological well-being. BMC Public Health 2021, 21, 104. [CrossRef] [PubMed]

29. Lai, J.; Ma, S.; Wang, Y.; Cai, Z.; Hu, J.; Wei, N.; Wu, J.; Du, H.; Chen, T.; Li, R.; et al. Factors associated with mental health outcomes among health care workers exposed to coronavirus disease 2019. JAMA Netw. Open 2020, 3, e203976. [CrossRef]

30. Morgantini, L.A.; Naha, U.; Wang, H.; Francavilla, S.; Acar, Ö.; Flores, J.M.; Crivellaro, S.; Moreira, D.; Abern, M.; Eklund, M.; et al. Factors contributing to healthcare professional burnout during the COVID-19 pandemic: A rapid turnaround global survey. PLOS ONE 2020, 15, e0238217.

31. Schaufeli, W.B.; Greenglass, E.R. Introduction to special issue on burnout and health. Psychol. Health 2001, 16, 501-510. [CrossRef]

32. Duarte, I.; Teixeira, A.; Castro, L.; Marina, S.; Ribeiro, C.; Jácome, C.; Martins, V.; Ribeiro-Vaz, I.; Pinheiro, H.C.; Silva, A.R.; et al. Burnout among Portuguese healthcare workers during the COVID-19 pandemic. BMC Public Health 2020, 20, 1885. [CrossRef]

33. Ahola, K.; Hakanen, J.; Perhoniemi, R.; Mutanen, P. Relationship between burnout and depressive symptoms: A study using the person-centred approach. Burn. Res. 2014, 1, 29-37. [CrossRef]

34. Wang, J.; Okoli, C.T.; He, H.; Feng, F.; Li, J.; Zhuang, L.; Lin, M. Factors associated with compassion satisfaction, burnout, and secondary traumatic stress among Chinese nurses in tertiary hospitals: A cross-sectional study. Int. J. Nurs. Stud. 2020, 102, 103472. [CrossRef] [PubMed]

35. Ruiz-Fernández, M.D.; Ramos-Pichardo, J.D.; Ibáñez-Masero, O.; Cabrera-Troya, J.; Carmona-Rega, M.I.; Ortega-Galán, Á.M. Compassion fatigue, burnout, compassion satisfaction and perceived stress in healthcare professionals during the COVID-19 health crisis in Spain. J. Clin. Nurs. 2020, 29, 4321-4330. [CrossRef]

36. Nanda, A. The Straits Time. More Doctors in Singapore Face Burnout, Anxiety amid the Pandemic. Available online: https: //www.straitstimes.com/life/more-doctors-in-singapore-face-burnout-anxiety-amid-the-pandemic (accessed on 5 August 2021).

37. Niedzwiedz, C.L.; Green, M.J.; Benzeval, M.; Campbell, D.; Craig, P.; Demou, E.; Leyland, A.; Pearce, A.; Thomson, R.; Whitley, E.; et al. Mental health and health behaviours before and during the initial phase of the COVID-19 lockdown: Longitudinal analyses of the UK Household Longitudinal Study. J. Epidemiol. Community Health 2021, 75, $224-231$.

38. Rossi, R.; Jannini, T.B.; Socci, V.; Pacitti, F.; Lorenzo, G.D. Stressful life events and resilience during the COVID-19 lockdown measures in Italy: Association with mental health outcomes and age. Front. Psychiatry 2021, 12, 236. [CrossRef] [PubMed] 
39. Yıldırım, M.; Özaslan, A. Worry, severity, controllability, and preventive behaviours of COVID-19 and their associations with mental health of Turkish healthcare workers working at a pandemic hospital. Int. J. Ment. Health Addict. 2021, 3, 1-5.

40. Pan, X.; Xiao, Y.; Ren, D.; Xu, Z.M.; Zhang, Q.; Yang, L.Y.; Liu, F.; Hao, Y.S.; Zhao, F.; Bai, Y.H. Prevalence of mental health problems and associated risk factors among military healthcare workers in specialized COVID-19 hospitals in Wuhan, China: A cross-sectional survey. Asia-Pac. Psychiatry 2020, 21, e12427. [CrossRef]

41. Spoorthy, M.S.; Pratapa, S.K.; Mahant, S. Mental health problems faced by healthcare workers due to the COVID-19 pandemic-A review. Asian J. Psychiatry 2020, 51, 102119. [CrossRef]

42. Mo, Y.; Deng, L.; Zhang, L.; Lang, Q.; Liao, C.; Wang, N.; Qin, M.; Huang, H. Work stress among Chinese nurses to support Wuhan in fighting against COVID-19 epidemic. J. Nurs. Manag. 2020, 28, 1002-1009. [CrossRef]

43. Ali, A.M.; Green, J. Factor structure of the depression anxiety stress Scale-21 (DASS-21): Unidimensionality of the Arabic version among Egyptian drug users. Subst. Abus. Treat. Prev. Policy 2019, 14, 1-8. [CrossRef] [PubMed]

44. Ali, A.M.; Alkhamees, A.A.; Hori, H.; Kim, Y.; Kunugi, H. The Depression Anxiety Stress Scale 21: Development and Validation of the Depression Anxiety Stress Scale 8-Item in Psychiatric Patients and the General Public for Easier Mental Health Measurement in a Post COVID-19 World. Int. J. Environ. Res. Public Health 2021, 18, 10142. [CrossRef]

45. Updates on Singapore's COVID-19 Situation. Ministry of Health Singapore. Available online: https://www.moh.gov.sg/covid-19 (accessed on 1 July 2021). 